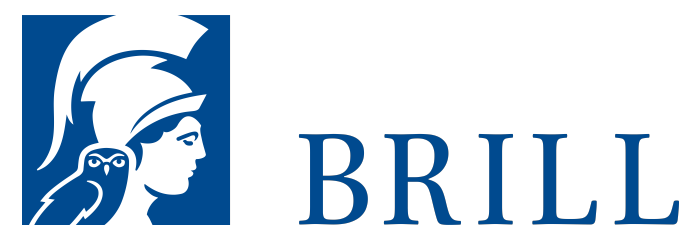

\title{
Sehnsucht nach dem Guten
}

Zum Verhãaltnis von Literatur und Ethik im epischen Werk Peter Handkes

Author: Tanja Angela Kunz

Wie viel Gutes braucht ein Werk, um als moralisches zu gelten? Wie viel Moral, um sehnsuchtsvoll zu bleiben? Und wie viel Sehnsucht, um am Guten festzuhalten?

Das Werk von Peter Handke ist eines der umstrittensten: Was sich in ihm vielfach als moralischer Anspruch zeigt, wird in der Kritik als narzisstische ÃœberhÃ ๆhung des Autors, als esoterische Botschaft oder romantisierende Weltvergessenheit bewertet. Gesch ̃̃atzt wurde lange Zeit die produktive Selbstsuche, die sich aus Handkes Texten herauslesen lã åsst, doch spÃatestens mit der VerÃ ๆffentlichung der JugoslawienSchriften hat das Werk in der Ã Iffentlichen Wahrnehmung â $€$ “ aus moralischer Perspektive â $€^{\prime \prime}$ ausgedient. Unter RÃ $1 / 4$ ckgriff auf zeitgenÃ | ssische ethisch-Ãasthetische Theorien wird das epische Werk des Autors auf seinen Status und seine Besonderheiten hin befragt.

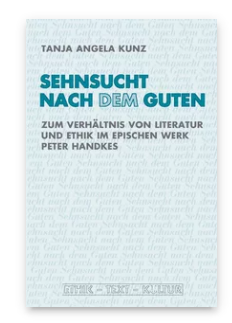

Pages: 489

Seiten

Language:

German

Subjects:

General,

Literature and

Cultural Studies

Publisher: Brill |

Fink

Series:

Ethik - Text -

Kultur, Volume:

12

E-Book (PDF)

Released online:

O4 Sep 2017

ISBN: 978-3-

8467-62o6-6

List price

Paperback

Publication date:

14 Jul 2017

ISBN: 978-3-

7705-6206-о

List price 
Studium der Neueren deutschen Literatur und Romanistik an der Humboldt-UniversitÃat zu Berlin. Abschluss 2009 als Magistra Artium. 2010-2013 Wissenschaftliche Hilfskraft im Deutschen Literaturarchiv Marbach. 2011-2013 Stipendiatin der der Elsa-Neumann-Stiftung des Landes Berlin. Promotion 2014 im Fach Neuere deutsche Literatur an der HumboldtUniversitÃat zu Berlin bei Prof. Dr. Ernst Osterkamp und Prof. Dr. Steffen Martus. Seit 2014 Vorlassverwalterin im Privatarchiv von Christa BÃ $1 / 4$ rger und Peter BÃ $1 / 4$ rger im Auftrag des Deutschen Literaturarchivs Marbach. 2015-2016

Wissenschaftliche Mitarbeiterin am Lehrstuhl von Prof. Dr. Ernst Osterkamp im Institut fã $1 / 4$ r deutsche Literatur der Humboldt-UniversitÃat zu Berlin.

Akademischer Titel: Dr. phil.

Derzeitige Position: Wissenschaftliche Mitarbeiterin am Institut fÃ $1 / 4$ r deutsche Literatur der Humboldt UniversitÃat und Leiterin des Heiner-MÃ $1 / 4$ ller-Archivs der HumboldtUniversitÃat zu Berlin.

For more information see brill.com

Order information: Order online at brill.com +44330 3330049 | customerservices@brill.com Submission information: brill.com/authors

Titles published by Brill | Fink, Brill | mentis or Brill | Schöningh: +49(o)71 5413279216 | brill@brocom.de 